\title{
Tratamento de grandes deformações de malha em simulações de escoamentos multifásicos
}

\author{
Luzia de Menezes Romanetto* ${ }^{*} \quad$ Fabrício Simeoni de Sousa \\ Departamento de Matemática Aplicada e Estatística, ICMC, USP, \\ 13566-590, São Carlos, SP \\ E-mail: luzia@icmc.usp.br, fsimeoni@icmc.usp.br,
}

\begin{abstract}
RESUMO
Simulações de escoamentos multifásicos são de grande interesse em aplicações práticas na indústria, em particular na indústria petrolífera. Vários processos dependem do entendimento físico de escoamentos envolvendo interação com partículas, sedimentação e separação de fluidos. Dos muitos métodos existentes para a simulação dos processos acima descritos, há um crescente interesse no aumento de precisão, o que levou ao desenvolvimento de estratégias que utilizam discretizações por elementos finitos em malhas dinâmicas e adaptativas, usando uma formulação ALE (do inglês, Arbitrary Lagrangian-Eulerian), juntamente com uma representação geométrica da interface. Neste sentido, este trabalho tem o objetivo de estudar e implementar estratégias robustas de controle e adaptação de malhas, em situações onde a malha dinâmica é sujeita a grandes deformações [1]. Uma biblioteca de algoritmos e rotinas foi então desenvolvida para este fim, implementando técnicas de controle e otimização da qualidade dos elementos da malha, técnicas de adaptação da interface entre fluidos com esquemas de conservação de massa, técnicas de mudanças topológicas e preservação de propriedades materiais, além de uma comunicação facilitada destas rotinas com códigos de simulação numérica de escoamentos multifásicos existentes.

Palavras-chave: Malhas dinâmicas, tratamento de interfaces em movimento, escoamentos multifásicos, $A L E$
\end{abstract}

\section{Estratégias para malhas dinâmicas}

Na formulação ALE temos como domínio um referencial fixo na malha, o qual se move arbitrariamente para acompanhar as superfícies em deformação e garantir a qualidade dos elementos internos. A qualidade de um elemento se relaciona com limitantes de erros do método dos elementos finitos, e é definida por critérios que podem depender do tamanho dos elementos, determinando elementos menores que demandam maior precisão; e/ou da forma dos elementos, evitando características geométricas como ângulos grandes, que podem causar grandes erros de interpolação [3].

Quando grandes deformações ocorrem, apenas movimentar a malha é insuficiente para garantir sua qualidade ou mesmo sua validez. Neste trabalho utilizamos a movimentação de malha dada pela suavização laplaciana, em conjunto com métodos de $h$-adaptação dados por operações de mudança topológica, como inserção de pontos, colapso e flipping de arestas.

Para que se obtenham malhas de alta qualidade, o critério utiliza uma medida sobre a forma dos elementos e um campo de tamanhos gerado por uma estimativa de erro a priori, definindo regiões de maior interesse como as superfícies [2]. A adaptação dinâmica é invocada sempre que a malha não satisfaz o critério, e empregada de duas maneiras: a primeira utiliza operações de inserção de pontos e colapso de arestas para satisfazer as restrições de tamanho, e outras operações para melhorar a forma dos elementos; a segunda define para cada ponto ou aresta da malha o mínimo dentre as qualidades dos seus elementos adjacentes, e então itera sobre esta lista em ordem ascendente de qualidade, testando um

${ }^{*}$ Bolsista de mestrado $\mathrm{CNPq}$ 
conjunto de configurações alternativas para cada região e alterando a malha para aquela que produz a melhor qualidade.

Para administrar a inserção ou movimentação de pontos associados a graus de liberdade da simulação numérica dentro do pacote de malhas adaptativas, estabelecemos uma função de callback que realiza a comunicação entre eles. Este callback é responsável por administrar os graus de liberdade de acordo com as operações de malha realizadas, e é inserido na assinatura das operações topológicas.

Outro problema enfrentado é o colapso de arestas nas interfaces em simulações multifásicas, que podem levar a uma transferência indevida de massa entre as fases. Para solucionar isto, o ponto de colapso é movimentado de modo a balancear a massa entre as fases, mantendo as quantidades físicas anteriores ao colapso.

Para testar a robustez dos métodos desenvolvidos, utilizamos dois modelos físicos aproximados que apresentam grande deformação: um modelo de deposição de partículas, onde são simuladas $N$ partículas sólidas imersas em um fluido sob ação da gravidade; e um modelo de ascensão de bolhas, onde uma bolha de fluido imersa em outro fluido mais denso ascende sob efeito do empuxo e tem sua geometria deformada. A figura 1 mostra o resultado da malha na simulação de deposição de partículas.

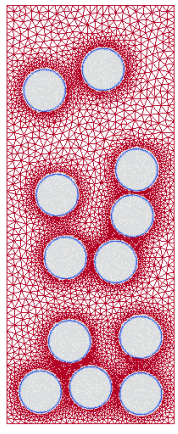

(a) Malha da simulação.

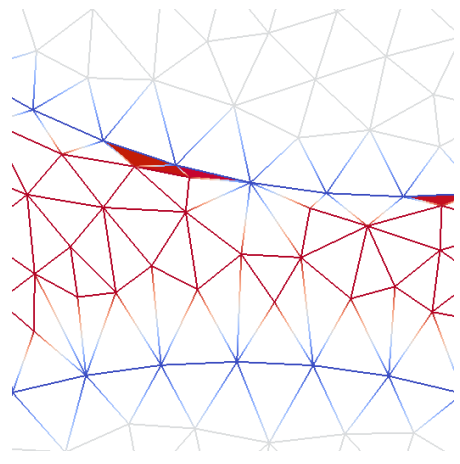

(b) Detalhe do trecho da malha cujos elementos não satisfazem ao critério de qualidade.

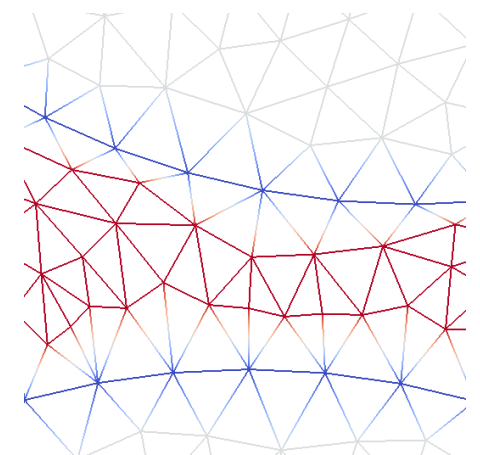

(c) Malha após adaptação.

Figura 1: Simulação de deposição de partículas, com adaptação dinâmica da malha.

\section{Conclusão}

A metodologia desenvolvida neste trabalho foi capaz de manter a razão de aspecto das células da malha acima de um critério estabelecido, melhorando a qualidade após deformações consideráveis, como ocorre no modelo ilustrado na figura 1. As adaptações não afetam as quantidades físicas de cada fase, preservando ao máximo as interfaces e se mostraram robustas para simulações com grandes quantidades de partículas.

\section{Referências}

[1] G. Compere, J. F. Remacle, J. Jansson, J. Hoffman, A mesh adaptation framework for dealing with large deforming meshes, International Journal for Numerical Methods in Engineering, 82 (2010), 843-867.

[2] S. Quan, Simulations of multiphase flows with multiple length scales using moving mesh interface tracking with adaptive meshing, Journal of Computational Physics, 230 (2011), 5430-5448.

[3] J. Shewchuk, What is a good linear finite element? Interpolation, conditioning, anisotropy, and quality measures (preprint), University of California at Berkeley, 2002.

[4] F. Montefuscolo, Métodos numéricos para escoamentos com linhas de contato dinâmicas, Dissertação de Mestrado, ICMC-USP, 2012. 